\title{
10
}

\section{A Stumble in the Dark: Contextualizing Gerry and Sylvia Anderson's Space: 1999}

Henry Keazor

'Space: 1999 occupies a unique and not altogether happy position in the Valhalla of televised space adventures. It is the program that Star Trek fans love to hate, even 20 years after its debut. When it is not being ridiculed or attacked, 1999 is often forgotten or overlooked by science fiction historians and television critics, probably because it was a British-made product that never aired on the major American television networks. Perhaps Space: 1999 's biggest problem is simply that it appeared at the wrong time. It stands sandwiched between Star Trek (1966-69) and Star Wars (1977), two milestones of the genre,' John Kenneth Muir writes in the introduction to his book Exploring 'Space: 1999,' published in $1997 .{ }^{1}$

Indeed, Space: 1999 does occupy a 'not altogether happy position' between other TV science fiction series. Although the show earned a certain amount of praise, is still acknowledged by some critics, and continues to enjoy an ever-increasing international fan cult status due to the fact that it was sold to more than 100 countries, the series, originally conceived and produced by Gerry (1929-) and Sylvia Anderson (1937-), mostly faced severe criticism. ${ }^{2}$ This was partly directed against the atmosphere of the series, which was accused of being somber, dull and obscure, and partly because of the way the stories were told. Critics described the plots of the stories as slow, lifeless and heavy-handed. The direction of the main characters and their stiff, formal and sometimes seemingly sedated and wooden acting skills were also criticized. Maliciously referring to the fact that the Andersons had made their first success on British television with children's puppet series like Thunderbirds, and with Space: 1999 aimed at live-action science fiction for adults, one critic wrote about the new series and the two American leading actors, Martin Landau and Barbara Bain: 'Gerry and Sylvia Anderson used to make the space stuff with puppets. With Martin Landau and Barbara Bain, I swear, you won't tell the difference. ${ }^{3}$

But in order to fully understand the originality of Space: 1999 and the reasons for its mixed reception, it is necessary to consider the historical context in which the series was produced. Space: 1999 was not only 'sandwiched between Star Trek and Star Wars,' as Muir stated, but also bridged two different times and their changing cultural, economic as well as social and scientific conditions, all of which had an impact on the series. ${ }^{4}$ 


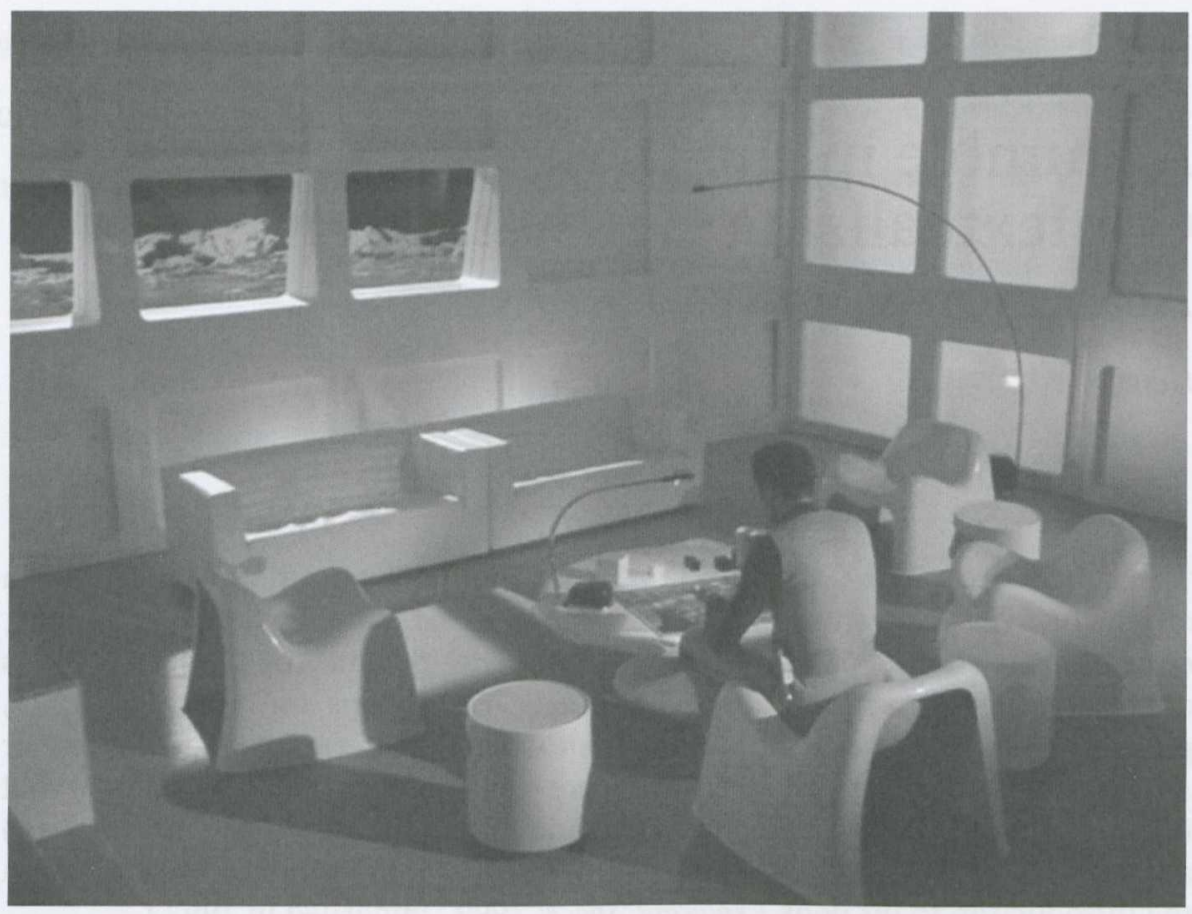

Figure 10.1 A view in Commander John Koenig's office on Moonbase Alpha, showing (under the windows) two 'Throwaway' sofas (1965), four 'Toga' chairs (1968) around a 'Mezzatessera' table (1966), flanked by three 'Giano Vani Route' telephone tables (1966).

Source: Space: 1999, episode 20, Space Brain (22 January 1976). Courtesy of Granada Ventures Ltd/ITV Global Entertainment Ltd/ITV Studios Global Entertainment.

Thus, despite the fact that the first season of the series was produced and shot between 1973 and 1975, and was supposed to show the reality of the then distant year 1999, the viewer continuously encounters examples of typical 1960s design, primarily conceived by Italian and international fashion designers: A 'Mezzatessera' round table conceived in 1966 by Vico Magistretti stands in the Commander's office (Figure 10.1) together with the so-called 'Selene' chair by the same designer. Completing this set of 1960 s furniture, the audience sees two 'Throwaway' sofas, designed by the Italian Willie Landels and distributed from 1965 by the Italian designer Aurelio Zanotta, as well as 'Toga' chairs, designed in 1968 by Sergio Mazza and manufactured by the Italian company Artemide, and finally three 'Giano Vano Ruote' telephone tables, designed in 1966 by Emma Gismondi Schweinberger. ${ }^{5}$

The mostly white colors, simple forms and smooth plastic surfaces of the set elements are accompanied by costumes designed by none other than Rudi Gernreich (1922-1985), the Austrian-born American fashion designer who rose to fame during the 1960s through his minimalistic clothing creations made of synthetic fabric, often shaped in, or ornamented with, geometric forms. For Space: 1999 Gernreich conceived a simple and austere unisex-uniform, whose bright, cream color was interrupted only by one colored sleeve (indicating the working area of 


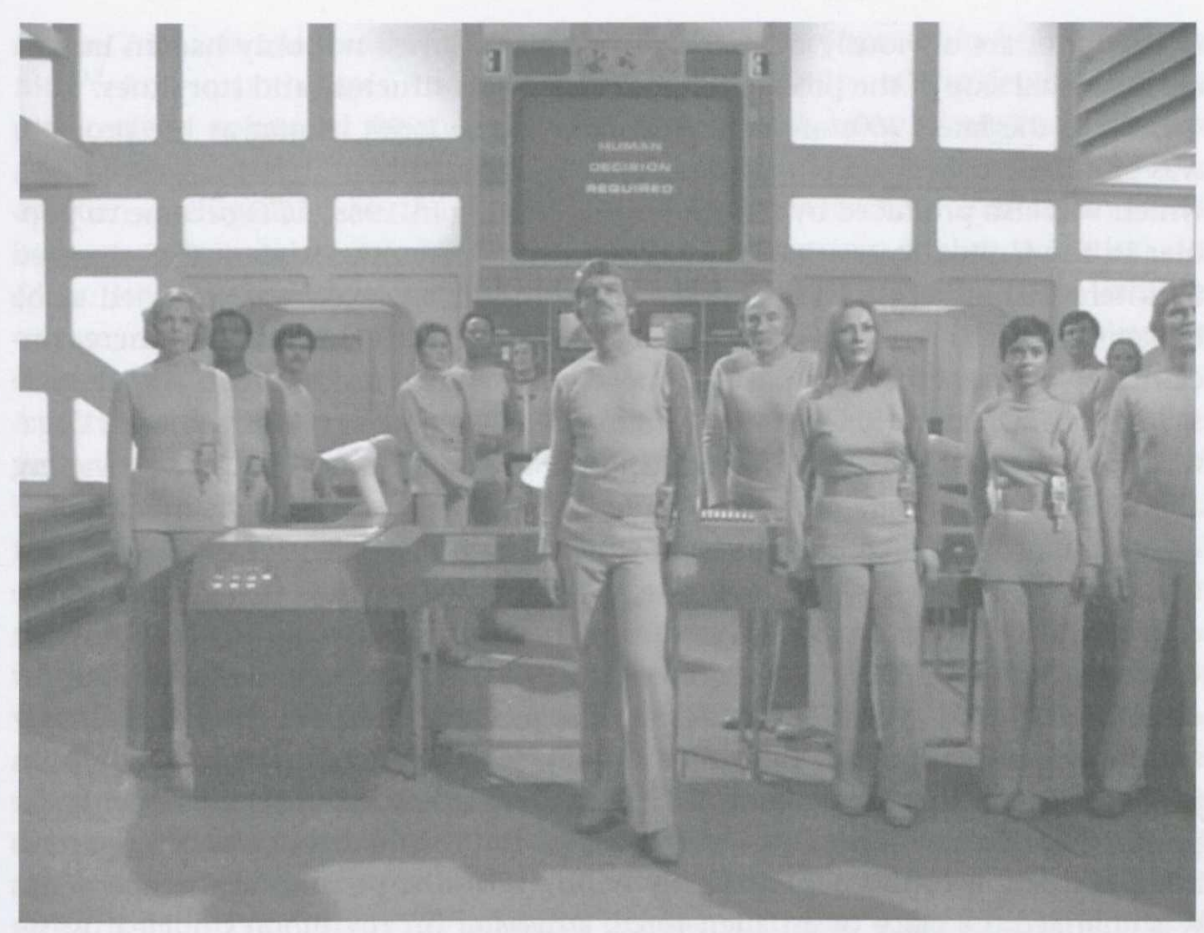

Figure 10.2 A look into the Command Center with the Moonbase Alpha crew in their unisex uniforms.

Source: Space: 1999, pilot-episode 1, Breakaway (4 December 1975). Courtesy of Granada Ventures Ltd/ITV Global Entertainment Ltd/ITV Studios Global Entertainment.

its wearer), zippers along the sleeve and the trouser-leg, and a yellow plastic belt (Figure 10.2). ${ }^{6}$

The sets and costumes thus showed a bright, smooth, clean and efficient-looking world which - given the heavy amount of plastic used for its fabrication and the strong lights coming from the plastic wall-panels - obviously did not know any shortages of oil or energy: This can be seen as either a nostalgic look back or an encouraging glimpse into the future, especially in fall 1973 when the energy and oil crisis in the Western hemisphere forced even England to introduce a threeday work week. As a matter of fact, the shooting of Space: 1999, which started in November 1973, was hampered by fuel shortages and the threat of strikes; the crew even had to organize a car-sharing system in order to get to the film studios which were, at the time, under the threat of closure. As a result, the production of Space: 1999 had to move from the Elstree Studios to Pinewood Studios where all of the sets had to be rebuilt. ${ }^{7}$

\section{1999/2001: seriousness and credibility}

The fact that the 1960 s are so visually present in the sets and costumes, which were themselves created in the early 1970 s in order to show a convincing vision of the year 1999, should make the viewer aware of the fact that different temporal layers . 
in the series are obviously inherent. ${ }^{8}$ These visual layers not only had an impact on the visual side of the production, but also on its structure and storylines.

Indeed, the late 1960s are also present in Space: 1999, insofar as the program was originally conceived as a spin-off of the then successful British TV-show UFO, which was also produced by the Andersons starting in 1969. UFO became so popular in the United States that in 1972 the American network giant CBS signaled its interest in buying a further series; the spin-off, however, was expected to be bigger, better and more spectacular than the first season. The main idea here concentrated on the especially popular moon base which, according to the premise set up in UFO, is part of S.H.A.D.O. (Supreme Headquarters Alien Defence Organization), a secret defense force fighting off the continuous attacks of invading aliens. These hostile enemies should come up with a plan to blast the moon out of its orbit in order to dispose of its base, which served as a defensive outpost against their attacks. The new series, therefore, was supposed to show the adventures the crew of the moon base experienced during their odyssey through space. But when viewer ratings for UFO suddenly dropped in 1972, the project of a new series, now called UFO: 1999 was cancelled, despite the fact that preproduction was already at an advanced stage and that much money, time and energy had already been invested. Given this investment, CBS nonetheless decided to go ahead with the production of a new series. ${ }^{9}$ However, in order not to endanger its possible success by associating it to the now suddenly failing UFO, the premise of the new series was changed. In place of an alien force, a disaster on the moon's nuclear waste dump would now serve as a means of catapulting the earth satellite out of its orbit and out into deep space. ${ }^{10}$

But despite the fact that not aliens, but ultimately humanity itself was responsible for the moon's odyssey, Space: 1999 still carried some of the inherently xenophobic bias of UFO in its storylines. Whereas a series such as Star Trek showed a universe where alien races had established, for example, a 'United Federation of Planets,' the encounters with aliens of both the crews of S.H.A.D.O in UFO as well as of the crew of the Moonbase Alpha in Space: 1999 had - as some frowning critics noted - mostly negative results.

This stands in contrast to another science fiction production with which Space: 1999 is closely linked. The circular arrangement of the moon base, its elevator launch pads, and the modular grid-and-girder structure of the space transporter used in the series - baptized as a nod to the first moon landing module named Eagle - bears a close resemblance to the moon base and its moonbus featured in Stanley Kubrick's 1968 film 2001: A Space Odyssey. ${ }^{11}$ Widely recognized as a milestone of the genre, Kubrick's film was compared to Space: 1999 , often to the latter's disadvantage. In addition to the fact that both narrate a space odyssey - 2001 focuses more on the aspect of odyssey as a metaphor for a shipwreck, while the TV series relies on the structure of Homer's Odyssey, only exchanging the different islands for planets - the productions are also linked by the special-effects designer Brian Johnson (1940-), who created the moon bases and space vehicles in both productions. He was later joined by Martin Bower (1952-) who, unlike Johnson, had not worked on 2001, but his design of a spacecraft used in the episode The 
Alpha Child was admittedly influenced by the Discovery spaceship from Kubrick's film. ${ }^{12}$ And in both cases, the seriousness and credibility of the depicted future purposefully enhanced the more mystical bias of both tales, where each time an alien, but obviously friendly force, seems to steer and direct the events. ${ }^{13}$ In 2001 , an alien intelligence lures the humans into deep space in order to establish direct contact and propel humankind on a journey leading to a higher evolution. In Space: 1999 it is made clear, slowly but surely throughout the first season, that the odyssey of the moon - though seemingly inspired by an accident provoked by humanity's short-sighted storage of nuclear waste on the earth's satellite - follows a destiny and purpose determined millions of years ago. This universal force intervenes and helps the Alphans, the inhabitants of Moonbase Alpha, during their expedition through space. ${ }^{14}$

\section{The Infernal Machine: techno-fascination and techno-skepticism}

Mysticism in both productions is accompanied by skepticism towards technology. Certainly in both 2001 and Space: 1999, technical progress seen in space stations, moon bases and spaceships is stylized as something fascinating because of its efficiency, power and even beauty. At the same time the limits of technical progress are clearly emphasized. HAL, the computer brain of the spaceship Discovery in 2001, has to be de-activated in the end because it goes berserk; both the dialogue and the action of Space: 1999 relate to the shared theme regarding the limits of human knowledge and computer intelligence. ${ }^{15}$ Not only is the whole premise of the series based on the assumption of a gigantic failure of human technology, leading to the explosion of the nuclear waste storage facility on the moon, but throughout the first season frequent references are also made to earlier, failed and ill-fated deep-space missions. ${ }^{16}$

This ambiguous attitude towards human technology, seen positively in the stylization of the carefully crafted models and the impressive special effects on the one hand, and negatively in the technology-related disasters on the other, also lies at the heart of earlier attempts by the Andersons to rival Kubrick's sci-fi masterpiece. ${ }^{17}$ In 1968 they wrote and produced the film Doppelgänger, directed by Robert Parrish (1916-1995), where the viewer encounters the same contradictory mix of enthusiasm and skepticism towards technology. Here, too, the details of space exploration technology are presented with great care and in a fascinating light: rockets, ramps, space suits, and even an attentively crafted manned docking maneuver, obviously inspired by the first unmanned docking between Gemini 8 and an Agena target vehicle, achieved in March 1966. Further, the show anticipated the real manned docking of Soyuz 4 and Soyuz 5, accomplished by the Russians in January 1969, nine months before the film's première. It is, however, not by chance that in the end, the whole rocket base with all its technological paraphernalia is destroyed by an automated shuttle during its unfortunate re-entry in one of the famous and typical, gigantic 'Anderson' explosions: already, the obvious fascination for the achievements of technology displayed on the show is counterbalanced by a deep skepticism not only towards the impossibility of controlling technology, but 
ultimately also towards its purpose. In Doppelgänger, a manned flight is secretly planned and realized by both the European Space Exploration Centre (EUROSEC) as well as NASA in order to explore a recently discovered new planet in the solar system, which hitherto had been hidden due to the fact that it is in the same orbit as earth, albeit on the opposite side of the sun. After a successful launch and flight to the planet, the shuttle of the English astronaut and his American colleague is hit by an electrical storm and crashes. While the American is critically injured, the English astronaut, when rescued, finds himself back on earth where his superiors accuse him of having willfully aborted the mission and returned to earth. Slowly, however, it dawns on the astronaut that he has not actually returned, but is on the newly discovered planet which turns out to be a duplicate earth, a mirror image of his own world. In order to prove this to his superiors, he tries to return to his still orbiting spaceship, but the maneuver fails - due to an opposed electrical charge. When crashing his shuttle, he destroys the entire base together with the control station, killing all the people involved in the secret project and leaving behind only EUROSEC director Jason Webb (who, in the end, cannot even be sure that it all was more than just a hallucination). Thus, the plot strongly implies that humankind, when leaving earth and steering into deep space, ultimately only encounters itself, with catastrophic results. ${ }^{18}$ Other Space: 1999 episodes frequently dealt with similar storylines, particularly in Another Time, Another Place and in A Matter of Life and Death, which also employ motifs of the opposed or plots in which anti-matter is unfolded.

\section{A Matter of Life and Death: the impact of the energy crisis}

This skepticism towards the effects and risks, as well as the achievement of technology in general and space exploration in particular, was obviously enhanced at the beginning of the 1970 s by the worldwide oil and energy crises, and the immediate necessity of inventing alternatives to traditional energy sources. A scene from the pilot episode of Space: 1999, Breakaway, further spins the idea that atomic energy would be a major response to this challenge: one of the characters remarks that 'atomic waste disposal is one of the biggest problems of our time.' This acknowledgment leads to establishing nuclear waste disposal areas on the far side of the moon, which in the end threaten to explode, transforming them into (as Commander Koenig puts it), the 'biggest bomb man's ever made. ${ }^{19}$ Ultimately, the explosions do catapult the moon out of its orbit. And when, in another episode (Another Time, Another Place) the moon temporarily returns to its orbit, it is the earth of the future which it now circles around, devastated by what seems to be a worldwide nuclear disaster that has covered the planet with radioactive ash. ${ }^{20}$

Given the impact that the energy crisis, with its shortages and subsequent strikes, had on the production of the series, it is little wonder that this situation left its mark on the plots of many episodes, in which the preciousness of energy repeatedly characterizes the storyline. ${ }^{21}$ In fact, the title of one of the episodes, A Matter of Life and Death, can in some ways stand as a headline for the whole Space: 1999 series which in its plots mostly revolves around the need of energy and 
the ensuing questions of death, survival and procreation. ${ }^{22}$ Interestingly, the topic of procreation in these stories is strongly linked to the idea of death as a necessity for understanding life. The concept of immortality, tackled twice by two episodes in the first season (Death's Other Dominion and The End of Eternity), is in both cases rejected. In Death's Other Dominion, survivors of a former Uranus expedition of 1986, stranded on the ice-planet Ultima Thule, have been granted immortality by their surroundings, but with the price of being chained to the planet and reproductively sterile. Their leader, Dr Cabot Rowland, wants to discover the secret of their own immortality in order to 'step forward into the greatest scientific adventure in the whole history of man.' 'Unencumbered by death, we shall leap from planet to planet, from solar system to solar system, from galaxy to galaxy!', he proclaims. But his experiments with some of his crew members have only led to their mental degradation, leaving them as 'living dead,' 'vegetables who sacrificed their minds to science.' It is due to the mortal Alphans, who serve as a positive mirror, that the immortal inhabitants of Ultima Thule eventually turn their backs on the search for the secret and engage instead in trying to heal the demented. The question asked by Commander Koenig at the end of the episode - 'Is it death that gives a meaning to life, in the end?' - is then indirectly answered in The End of Eternity where the Alphans have to fight a character called 'Balor.' Balor himself is a criminal who has been exiled and jailed by a civilization of immortal aliens because, as his character claims, he was trying to bring back meaning and purpose to their sterile and apathetic lives by sowing chaos, terror, destruction and torture. As Balor exclaims, 'We tried to instill in the minds of our people the thought that only death gives a purpose to life, that a full response to life can only be measured against a fear of death. But how can you value life, if you do not fear death?'

\section{The Space Ark: predestined purposes}

The Alphans are thus continuously confronted with basic biological notions such as death and life, and connected processes like nourishment, procreation, evolution and even phylogenesis (in one episode they are pushed back to the evolutional stage of Cro-Magnon). All this makes clear that they are taking with them the basic elements of the natural human life they seemingly had to leave behind on earth when thrust on board their artificially created base on the sterile moon and into their deep-space odyssey. But in fact, it is repeatedly hinted at during the development of the series that the positive consequence is that their errant ways allow them to carry human life with them into deep space, dispersing it to dead planets and bringing them, respectively, back into life. ${ }^{23}$

This concept is particularly played out in two further episodes which, despite the fact that they are chronologically quite far from each other, are closely linked. In episode 6, Another Time, Another Place, the Alphans are colonizing a future earth, which humanity has devastated by radioactivity, while in the last episode of the first season, The Testament of Arkadia, they discover the planet Arkadia, from which the ancestors of humankind once fled after they had destroyed their own world. 
Taking plants and animals with them, the Arkadians did find earth, inhabited and colonized it, but - as Another Time, Another Place depicts - they obviously fell back on their errors, destroying the new planet the same way they destroyed their home planet, Arkadia. In this episode, a man and a woman from the Alpha crew follow an imperative spelled out in the message: 'You who are guided here, make us fertile, help us live again.' Thus, both home planets of humankind, earth and Arkadia, are in the end brought back to life again by the Alphans and the circle is complete. 'The seeds from earth, so carefully stored and nurtured by us, had returned to their place of origin,' Commander Koenig concludes in the Arkadia episode, this being a clear sign of the original idea, according to which the entire series should have been titled The Space Ark. ${ }^{24}$

In the earlier episode Mission of the Darians, this notion of procreation as a biological and universal imperative is rehearsed in the encounter of the Alpha crew with another space ark when they cross paths with a nearly extinguished alien race, traveling from their destroyed home world Daria in a giant space city to a very remote 'virgin planet' in order to restart their civilization with the help of a tersely defended gene bank. A disaster, tellingly very similar to the one which blasted the Alphans out into space (a nuclear reactor exploded), has severely damaged the space city and poisoned all survivors with radiation. Their ruler, Neman, tries to convince the Alphans to join the mission of the Darians by spelling out the parallels between the Alphans, Noah's Ark and themselves. He stresses the fact that these allegories all fulfill the same purpose: to preserve and transport life to another place and to make it flourish again there.

But the Darians are only seemingly defending their civilization when protecting their gene bank, which contains the undamaged genetic material of their race from which, in the future, 'pure, healthy Darians' should stem. In reality, the Darians have already renounced all civilized behavior. They feed on (according to them) 'degenerate creatures, savage, mutant, cannibal' respectively and use them as living organ pools in order to prolong their own sterile lives. Ironically, they defend their horrible deeds with Darwinist elitism: 'to preserve only the fittest.' Thus, it becomes clear that author Johnny Byrne (1935-2008) has given the Darians a name that rings very similar to the notion 'Arian' in order to emphasize the fascistic nature of their thinking and acting. ${ }^{25}$ Not to have fought for their survival is ultimately the crime of the Darians for which they are punished: for they have lost respect for life itself and have betrayed the present both in the name of the worship of life's artificially extracted and condensed essence, the gene, and in the name of the future it seemingly stands for. The Alphans, instead, while trying to find a new home for themselves in the first place, are bringing (back) life to hitherto lifeless planets as a positive side-effect. But that this reanimation ultimately follows a predestined purpose is made clear by Arra, the mysterious inhabitant of a huge spaceship the Alphans encounter in the episode Collision Course. When Koenig speaks of the explosion that catapulted the moon out of its orbit as an 'accident' nobody could have foreseen, she pities him because he is belittling himself in the scheme of things, and when he asks about the destiny of his crew and himself, she answers: 'You shall continue on; your odyssey shall know no end; you will prosper 
and increase in new worlds, new galaxies; you will populate the deepest reaches of space.'

In light of this prediction, the title of the first episode, Breakaway, which depicts the explosion that launches the moon into deep space, also takes on a positive aspect. It hints at the fact that the moon breaks free and away from earth in order to go on its destined odyssey that will ultimately guide it to the dead cradle(s) of humankind, with the purpose of reviving them, thus also answering Koenig's closing doubts in The Testament of Arkadia: 'We still wander the emptiness of space [...]. We must keep faith and believe that for us, for all of mankind, there is a purpose. $^{26}$

The idea of a migration into space, according to which humankind should venture into deep space, and thus colonize it (in order to assure the survival of the human race in case of a global disaster), had already been put forward in 1929 in The Aims of Astronautics. Written by the Russian Soviet rocket scientist Konstantin Tsiolkovsky (1857-1935), who, for this purpose, had also proposed 'generation star ships' such as the one built by the Darians, the theory was then taken up with a different bias by the American physicist Gerard K. O'Neill (1927-1992). ${ }^{27}$ O'Neill not only organized a small conference on space colonization in May of 1974, but also published a highly influential article, entitled 'The Colonization of Space,' in Physics Today in September 1974, exactly when author Johnny Byrne was preparing the script for Mission of the Darians. ${ }^{28}$

\section{Earthbound: science fiction and contemporary issues}

It is no surprise that the writers of Space: 1999 should have taken notice of such developments in the context of space exploration, given that they continuously paid attention to the past and present of space exploration during the production of the series. But like their general attitude towards technical progress, their feelings regarding space exploration were also, clearly, ambiguous. On the one hand, photos from real space and moon explorations appear repeatedly, giving the series a touch of authenticity (or, perhaps, simply as a nod towards the accomplishment of NASA). ${ }^{29}$ For instance, a photo of the Skylab 2 mission, taken by the departing crew during their final inspection flight on 22 June 1973, is visible on the board of the scientist Professor Victor Bergman (Figure 10.3) in Ring around the Moon, filmed in March 1974. This image, however, takes on a slightly different meaning because of the context of the story told in the episode. ${ }^{30}$

On the other hand, referring to the launch of probes during the production of the series, Space: 1999 deals twice with the consequences of such an exploration by encompassing a different perspective each time. In Ring around the Moon, the Alphans have to face the consequences of an alien probe which recklessly, and without any regard concerning possible victims, collects its data despite the fact that the planet from whence the probe had been sent no longer exists. In the context of a story about an alien deep-space probe out of control, the photo of the mutilated Skylab - with one remaining solar panel and a rigged parasol solar shield to replace its missing micrometeoroid shield - could serve as a discrete, yet 


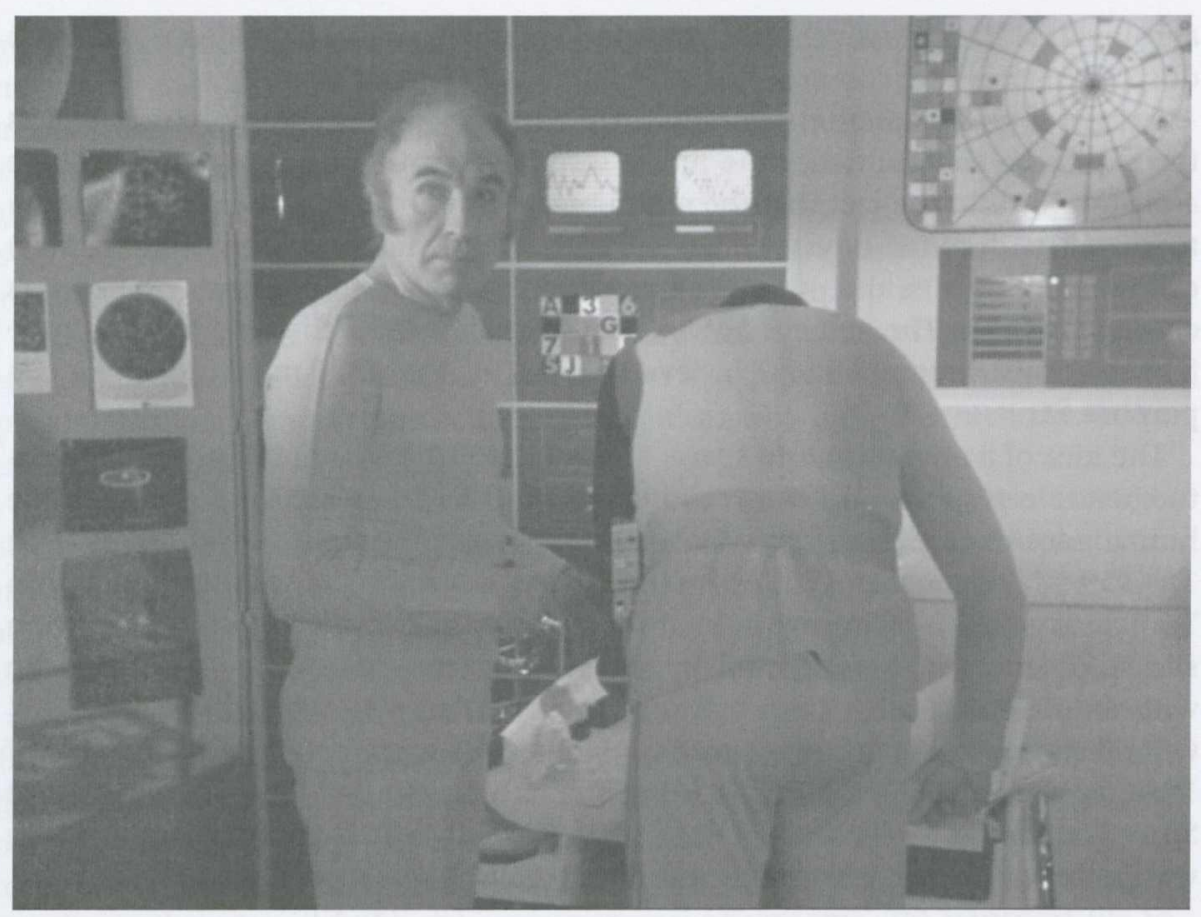

Figure 10.3 Professor Bergman with a photo of Skylab 2 on the wall of his laboratory.

Source: Space: 1999, episode 4, Ring around the Moon, 15 January 1976. Courtesy of Granada Ventures Ltd/ITV Global Entertainment Ltd//ITV Studios Global Entertainment.

still visible admonition to think about the probes humanity has launched. Further, it points to the obvious consequences they could have while being out of reach or control, a connection underlined when Professor Bergman compares the threatening probe to similar efforts of humankind: 'They're a sort of reconnaissance team, sent out into space to gather information and then transmit it back to Triton. That's all. We did it ourselves with our deep-space probe ships.'

The Alphans later have to deal with exactly one of these 'deep-space probe ships' from earth in Voyager's Return, filmed in August 1974, an episode which goes further than Ring around the Moon in questioning the consequences our own probes might have. In this episode the fictitious probe, 'Voyager One,' turns out to be equipped with the deadly, so-called 'Queller Drive,' 'an atomic engine used for going across space at incredible speed. [...] Incredible speed produced by fast neutrons spewed out into space, annihilating everything in their path. You'd survive better standing smack in the middle of a nuclear explosion.' When crossing the path of the moon, the probe threatens to destroy the base. However, its engine is switched to a harmless landing device based on ordinary chemical rockets, thanks to the German scientist Ernst Queller, founder of the 'Queller Drive,' who reveals that he has been among the crew along under the assumed identity of Ernst Linden. Queller took this name out of shame after a horrible accident when the twin probe 'Voyager Two' switched to the Queller drive too early during its launch and 
killed an entire community of 200 people. But immediately after the danger of 'Voyager One' has been avoided, another threat is revealed: During its exploration the probe has obviously played havoc with the two planets of an alien civilization, the Federated Worlds of Sidon, whose survivors have sent Chief Justifier Aarchon, together with a fleet, on the probe's trail in order to find the planet from where the deadly device has been launched and to destroy it in revenge. Given that the Alphans are former inhabitants of planet Earth, they are also held responsible by Aarchon: 'Once we have located planet Earth, your colony here will be extinguished.' Thus, the scientist Ernst Queller is again confronted with the terrible result of his invention, which he had originally conceived as a means to help 'further the boundaries of man's knowledge.' As Queller pleads, 'My purpose was to unite a divided world, to reach out in the name of science and humanity, to illuminate the mysteries of space, to seek out other worlds [...] and offer the hand of friendship.'

In 1982, the author of the episode, Johnny Byrne, confirmed that Ernst Queller's character, including his name and the elements of his invention, are partly indebted to the 'Father of the H-Bomb,' the Hungarian-American scientist Edward Teller (1908-2003); hence, the reference to 'You'd survive better standing smack in the middle of a nuclear explosion' and the good intentions put forward in defense, and partly to the rocket engineer Wernher von Braun (1912-1977), who also tried to defend his involvement with the Nazi government by referring to his noble goals of traveling to the stars, an achievement that would unite a world divided by the Cold War. ${ }^{31}$ The reference to von Braun is even emphasized by the fact that his alien victims are coming from a planet called 'Sidon,' which - if taken literally refers to the port in Southern Lebanon, one of the chief cities of the Phoenician empire in 1200-650 BC, but which - with the central letter 'd' cut out - reads like 'Sion. ${ }^{\text {'32 }}$

But the plot of Voyager's Return not only looks back at the people involved in pushing forward the technical progress of science, but it also casts a glance at the then still ongoing launch of probes, while fantasizing about the possible consequences of such activities. In retrospect, it is quite telling that author Johnny Byrne got his chronology mixed up when reversing the relations between fact and fiction while claiming that the plot struck him as 'quite impressive in a way because the Voyager probes were out there at that time.' ${ }^{33}$ As a matter of fact, the filming of the episode took place in 1974 while the launch of the real Voyager probes (as in the series there were 'Voyager' 1 and 2, though they were actually named only in 1977) happened in August and September 1977. ${ }^{34}$ Byrne's 'Voyager' pair is thus likely to have been inspired by the earlier twin probes Pioneer 10 and Pioneer 11, launched in March 1972 and April 1973, which indeed 'were out there at that time.'

\section{The Troubled Spirit: mirror images}

At the same time, Voyager's Return demonstrates that the above-stated xenophobic depiction of aliens in Space: 1999 must also be put into perspective. The aliens are 
not just evil, they have a motive for seeking revenge on the humans. Ultimately, the Sidons' mistake is not that they are hunting down the civilization responsible for sending the deadly probe, but that they are unwilling to reason and revise their judgment even when they learn that behind the genocide stood a tragic technical failure for which the Alphans cannot be made responsible. By insisting on his judgment, Aarchon is guilty of the same 'pride and arrogance' of which Queller in the end did blame himself, showing that in Space: 1999 human and alien beings do serve as a sort of a mirror of each other. They share the same needs, as seen in the episode Force of Life, where the alien creature craves precious energy, just as the Alphans had, and aliens react to the weaknesses and mistakes of humankind (such as in Voyager's Return). Moreover, the alien surroundings occasionally function as a passive, reflecting screen which simply confronts the Alphans with themselves. This occurs, for example, in an episode entitled War Games, in which inherent human fear leads the Alphans to imagine themselves in vivid hallucinations of war, death and destruction. In Full Circle, the Alphans are reduced to the state of Cro-Magnon man and, deprived of the capacity to speak, are forced to live out the emotions of frustration, which results from their misunderstandings. ${ }^{35}$ The humans thus encounter mirror images of their own problems (shortage of energy, war), the echoes of their deeds (carelessly sent probes) and of their shortcomings, which partly reflect the typical challenges and questions of the early 1970s, many of which we still face today.

\section{The Space Brain: cosmic intelligence}

Some of the answers indicated do, however, also point back towards the early 1970s. In Space: 1999, reference is frequently made to a mysterious 'cosmic intelligence' which, through all seemingly accidental and fortuitous events, actually assures the Alphans that they all serve a purpose and contribute to the fulfillment of a bigger scheme. Behind this concept clearly stands Edgar Mitchell's (1930-) idea of an intelligence in the universe, which he experienced as a sort of 'epiphany' during his return from the moon as astronaut on Apollo 14 in $1971 .{ }^{36}$ Leaving NASA a year later, Mitchell then founded the Institute of Noetic Sciences (IONS) in January 1973, aiming at a reconciliation of science with religion. According to Mitchell, consciousness itself is the point at which science and religion meet. It is also this connection which connects the cosmic consciousness with the individual consciousness: the key to the universe is contained in our minds and vice versa. According to Mitchell, the kind of epiphany he experienced during his flight is 'a latent event in every individual. ${ }^{37}$

Space: 1999 shows traces of this concept of 'cosmic intelligence' or 'universal consciousness,' developed and publicized by Mitchell ever since his return to earth, particularly in the wake of Richard Maurice Bucke's book Cosmic Consciousness: A Study in the Evolution of the Human Mind, published in 1901. Not unlike Mitchell's description of his 'epiphany,' Bucke described and examined his experience of the universe as a living presence. 
In the episode The Black Sun, while traveling through a black hole and expecting nothing other than annihilation, the Alphans do encounter this 'cosmic consciousness.' It seemingly not only protects them against the immense forces of the black hole, but also reunites them against all odds with a survival ship they have sent in the opposite direction in order to save at least six crew members. 'Something brought us home,' one of the passengers of the survival ship concludes, after reuniting with friends and colleagues. Already this 'sense of order' is akin to Mitchell's concept of the 'Quantum Hologram' which, as a proof of the existence of 'cosmic consciousness,' keeps related particles connected even if separated through an immense distance. ${ }^{38}$ But the idea that such a 'consciousness' can also reveal itself to anybody when a certain 'syntony' is established, is depicted in Space: 1999 when both Koenig and Bergman begin to wonder how and why they survived the journey through the black hole. ${ }^{39}$ Their dawning realization is prepared by a dreamlike, illuminating experience during their passage though the black hole, where their dialogue also echoes parts of Mitchell's 'epiphany.' While the void suddenly seems alive for the Apollo 14 astronaut, Koenig and Bergman perceive the whole universe as 'living thought' where 'every star is just a cell in the brain of the universe. ${ }^{\prime 40}$ Just as Mitchell had tried reconciling science with religion, Professor Bergman points out that 'the line between science and mysticism is just a line.'

All this demonstrates that 'noetically' gained knowledge and science, according to this view, are by no means opponents - on the contrary. Again in concordance with Mitchell's philosophy that 'true spirituality' and 'true science [...] are looking for the same thing,' science in Space: 1999 can actually guide to the point where the 'cosmic conscience' can then be encountered and experienced..$^{41}$

\section{The Age of Extremes: optimism and crisis}

In his book Age of Extremes: The Short Twentieth Century, 1914-1991, English historian Eric Hobsbawm divides the era from the beginning of the First World War to the fall of the Iron Curtain into three periods. The second, called 'The Golden Age,' represents the greatest period of economic expansion, running from the end of the Second World War to exactly the end of the year 1972, followed by an era of 'Landslide' marked by 'Crisis Decades.' As Andrew Smith has observed, this Golden Age and its fallout coincides precisely with the conclusion of the Apollo program which ended with Apollo 17 in December 1972. In Smith's view, this fact confirms that, with this last manned moon landing, an era of 'upheaval, [...] optimism and energy' ended, one that - economically, socially and psychologically had made the Apollo program possible, which in turn had marked and colored this 'Golden Age.' This age was followed by a generation which - due to upcoming financial, technical and political crises - was far more skeptical, disappointed and pessimistic. ${ }^{42}$

Space: 1999, conceived and produced by Gerry and Sylvia Anderson during this watershed period between 1972 and 1973, can be described as being also 'sandwiched' between these two eras of 'upheaval, [...] optimism and energy' on 
the one hand, and 'landslides' and 'crisis' on the other. ${ }^{43}$ Given the historical nature of the period in which the show was created and filmed, it is not surprising that the series would be imprinted with an ambiguous attitude towards space exploration and technology. As stated above, the attentive and detailed creation of the sets for a future moon base, perfected with lovingly crafted models and ambitious special effects, shows untroubled and unclouded enthusiasm and fascination for technology. Importantly, it testifies, through the bright colors of sets and costumes, a certain level of optimism. However, the dark, elegiac, and sometimes bleak and mysterious stories told in these sets, are deeply rooted in a profound skepticism regarding technology and its aftermath. Ultimately, it expresses a troubled consciousness of the limitations of human knowledge and an outright pessimism towards the possibilities of controlling human behavior and destiny.

The creators of Space: 1999 were perhaps particularly appropriate for communicating these mixed feelings, given that they had already shown similar tendencies in their first feature film Doppelgänger, released in 1969. The film, confirming Andrew Smith's view 'that Apollo was an emanation of popular culture before it was anything else,' on the one hand serves the viewer with glimpses into the spectacular preparation and training of the hero astronauts, but on the other hand also comes up with sometimes rather disheartening insights into the political and private background of space exploration. ${ }^{44}$ Thus, as early as 1969 , Doppelgänger depicted NASA as an organization whose decision to fund a projected flight to a newly discovered planet is not triggered by scientific idealism or curiosity (on this basis the funding was initially denied in the film narrative), but only by the fear that a political force other than the United States could be the first to explore and lay claim to the planet. And despite the fact that the phenomenon of marital breakdowns and increasing divorce rates among astronauts was considered shameful, and hence censured and concealed by NASA in the 1960s, the film perhaps because it was a British production - shows the failure of the American astronaut's marriage. ${ }^{45}$ Nevertheless, the final message of the film - namely that humankind ultimately only encounters itself in space - is still in line with 2001 . Similarly, author Arthur C. Clarke in 'Space Flight and the Spirit of Man' wrote in 1961 of the general feeling of humanity: 'We are in the grip of some mysterious force or Zeitgeist that is driving us out to the planets, whether we wish to go or not.' ${ }^{46}$ In 2001 as well as in Doppelgänger, humanity decides to follow this siren call out of curiosity and the spirit of adventure; but in Space: 1999, the words 'whether we wish to go or not' do get another meaning, because here the crew of Moonbase Alpha actually only involuntary veers away from earth and into deep space. Unlike Star Trek, the breakaway of the first episode is not a planned and controlled start of a five-year mission with precise duties and projects, but an endless odyssey defined by fear, anxiety and nostalgia. The adventurers are only partly comforted by the thought that they, too, are unwillingly on a mission that has been mapped out, though without their knowledge, by a mysterious 'cosmic intelligence. $^{47}$ 
It is, therefore, little wonder that Koenig bitterly rephrases Neil Armstrong's first words when stepping out onto the earth's satellite. While reflecting over the mission of a projected landing on a planet passing the solar system, and while facing threatening technological failures which will then lead to the disastrous explosion which ultimately kicks the moon into deep space, Koenig says to himself: 'A giant leap for mankind. It's beginning to look like a stumble in the dark.' It is a dark faintly illuminated by often discomforting mirror images from earth and humankind. It is thus too early to mourn together with Andrew Smith for the loss he attributes to the Apollo program when arguing that 'in the Sixties, some feared that Apollo would destroy the moon's value as the most elastic symbol or metaphor since God.' Perhaps exactly because they did send the moon and its moon-base crew into deep space and thus out of the reach of humanity's grasp, the producers of Space: 1999 were able, even after the Apollo program, to use 'space and the moon' again as 'canopies across which you could spread the psyche. ${ }^{48}$

\section{Notes}

1. John Kenneth Muir, Exploring 'Space: 1999': An Episode Guide and Complete History, London: Jefferson, 1997, 1.

2. Gerry and Sylvia Anderson split up after the first year of Space: 1999, and Sylvia Anderson left the production of the series. In this chapter only the episodes from the first season will be discussed because, with the arrival of Fred Freiberger (1915-2003) as the new producer in 1975, the series took a very different approach, which - with its inflationary, action-based stories, often involving silly monsters - was heavily modeled on the expectations of the US market and included a more colorful and eye-catching visual style. Because the second year tried to be very 'up to date,' even concerning its music, it has aged much more than episodes from the first season, which were meant to be a relatively timeless representation of the future.

3. Quoted from the film Space: 1999 Documentary, produced and directed by Tim Mallett and Glenn Pearce, Fanderson, 1996. This reproach might also have been due to the title sequence of the show where Landau and Bain were introduced in a very stiff and almost puppet-like way.

4. Star Wars director George Lucas (1944-) was so impressed by the special effects in Space: 1999 that he visited the studios during the filming of the episode War Games in 1974. From this episode he also borrowed the sight of a giant spaceship flying overhead the camera as shown in the opening of Star Wars; see http://www.space1999. net/ catacombs/main/epguide/t17wg.html (accessed 10 August 2011); and Jonathan W. Rinzler, The Making of Star Wars, London: Random House, 2008, 102-3, 412. Rinzler reports that, following his visit, Lucas changed the already approved design of the Millennium Falcon because it looked too similar to a spaceship shown in the episode. This might seem strange given that Space: 1999 and Star Wars have very different approaches towards science fiction and concerning their distribution, with Star Wars belonging more to the science fantasy genre and being presented as a cinema blockbuster, but it shows how much Lucas was impressed by Space: 1999 's special effects.

5. See http://www.space1999.net/ sorellarium13/alphan-furniture.htm (accessed 10 August 2011).

6. Gernreich had already developed such a design in 1972; see Brigitte Felderer, ed., Rudi Gernreich: Fashion will Go out of Fashion, Cologne: Du Mont, 2000, 156. The whole uniform obviously echoed Gernreich's famous as well as notorious 'UNISEX Project' which in the 1960 s challenged basic social assumptions regarding gender rules, limits and 
taboos. See, for example, Peggy Moffit and William Claxton, eds, The Rudi Gernreich Book, Cologne: Taschen, 1999, 184.

7. Pierre Fageolle, Cosmos: 1999. L’Epopée de la blancheur, Pézilla-la-Rivière: DLM, 1996, 54.

8. The same holds true concerning some of the architecture shown in Space: 1999. In the episode Missing Link the buildings of the alien dwellings on Zenno clearly rely, for example, on designs published by the Japanese architect Arata Isozaki in L'Architecture d'aujourd'hui 117 (November 1964/January 1965), xxv. It is obvious that all these 1960s decorations were also chosen for their 'futuristic' look, but it would be too easy to accept this as an already sufficient explanation for such a choice, given that for the earlier Anderson series UFO other items were used in order to depict the design of a differently looking future. The mere reference to the 'futuristic' look chosen for Space: 1999 is insufficient, and deeper analysis must rather ask: what type of imaginary future was the series supposed to depict? Space: 1999 actor Prentis Hancock commented that 'in some ways it was a '60s series, in the '70s.' See Robert E. Wood, Destination Moonbase Alpha: The Unofficial and Unauthorised Guide to SPACE: 1999, Prestatyn: Telos, 2010, 279 and 71, for a similar statement.

9. The project probably triggered the (today almost forgotten) TV series Moonbase 3, also a co-production of a British company (here the BBC) and American companies (Twentieth Century Fox and the $\mathrm{ABC}$ network). The series, created by the Doctor Who producer Barry Letts (1925-2009) and script editor Terrance Dicks (1935-), was commissioned in December 1972 by the BBC and aired in Britain in the fall of 1973. It only ran for six episodes and turned out to be a commercial and critical failure. Unlike Space: 1999 it was produced on a much more modest scale and had quite talkative scripts; similar to the Anderson series, it tried to depict a technically realistic vision of a future moon base and was also criticized as being too slow in its narration. See Steve Rogers, Moonbase 3: The Pictorial Compendium, London: The Mausoleum Club, 2004.

10. Space: 1999 Documentary; Fageolle, Cosmos: 1999, 20-1; Muir, Exploring, 6-7. This supports analysis of the moon's role in contemporary science fiction. For example, Michael Salewski, Zeitgeist und Zeitmaschine: Science Fiction und Geschichte, Munich: dtv, 1986, 99, argues that actual human exploration of the moon has 'caught up' with science fiction, and science fiction writers no longer know what to do with this celestial body - this is why the moon in the Anderson series Space: 1999 served as a 'footboard' and catapult for the proper journey into space.

11. See also the parallels given with the dates, both revolving around the year 2000 . Another, rather apocryphal and perhaps tongue-in-cheek reference to the first manned moon landing might be seen in the name given to the former commander of the moon base whom the new commander Koenig is about to supersede. His name, 'Gorski,' and the words he says to Koenig ('If you want to talk things over before I leave, I shall be in my quarters. Good luck.') might refer to the phrase Neil Armstrong is (as we know today: wrongly) supposed to have said during the first moon landing: 'Good luck, Mr Gorsky,' thus addressing a former neighbour from his boyhood whose wife was incredulous about Armstrong one day landing on the moon, and thus allegedly promised her husband a special erotic gratification in case Armstrong should succeed; see for this 'urban legend,' Andrew Smith, Moon Dust, London: Bloomsbury, 2005, 27.

12. Fageolle, Cosmos: 1999, 49. Some particular scenes from Space: 1999 were also visually influenced by 2001. A production sketch for the encounter with an alien probe in the episode Ring around the Moon, showing close similarities to the final traveling sequence in 2001, was probably not realized in the end because the probe is too negative and subordinated to associate it with the alien intelligence hinted upon in 2001. In the pilot episode Breakaway, however, some realized visuals are clearly indebted to scenes from 2001; see Fageolle, Cosmos: 1999, 54.

13. It was perhaps also this indebtedness to 2001 which earned Space: 1999 its hostile reception from the fans of Star Trek since the seriousness of Kubrick's intended 'proverbial 
good science fiction movie' was often put forward against Gene Roddenberry's (19211991) TV series which, in that confrontation, obviously appeared as 'cheap' and 'rather childish.' For Kubrick's intention, see Arthur C. Clarke, The Lost Worlds of 2001, London: Sidgwick \& Jackson, 1972, 17.

14. See especially the episodes Black Sun or Collision Course.

15. See the quotations below from the episode Earthbound.

16. See, for instance, the failed expedition to planet Meta in Breakaway; the doomed 'AstroSeven'-mission of Dr Russell's husband whose ship was incinerated while locked into an orbit around Jupiter in Matter of Life and Death; the failed Uranus-expedition in Death's other Dominion; and the disastrous mission of the manned probe to the planet Ultra in Dragon's Domain.

17. The goal was to transfer the cinematic style and the quality of the special effects from 2001 into a TV format. The budget for the series granted in order to achieve this 300,000 dollars per episode - was quite exceptional for a TV series if, for example, compared to the above-mentioned, rather modest Moonbase 3 (cf. note 9 above) - and the result impressive; Fageolle, Cosmos: 1999, 22.

18. See also the film's trailer which asks: 'Apollo 11 has conquered the moon! Where to NOW in space?' The answer implied by the film is this: Back to earth and back to ourselves. Fageolle, Cosmos: 1999, 9, finds it revealing that the moon's movement towards the exterior in Space: 1999 is actually answered at the same time by a movement towards the interior, thus making the explorer always encounter himself.

19. In the opening titles the nuclear waste area is described as being on the 'dark side of the moon,' a (common) error given that there is no 'dark' but just a 'far' side, as Isaac Asimov already noted in: 'Is "Space 1999" More Fi Than Sci?,' New York Times (28 September 1975), Sect. 2, 1.

20. This returns, slightly varied, in the second season with the episode Journey to Where, in which the earth has been devastated by human industrial pollution.

21. From the 24 episodes of the first season, eight deal directly with the imperative necessity of energy for survival. See, for this, episodes such as Earthbound (where a deserting crew member blackmails the commander by threatening to destroy a central unit from the power station); The Testament of Arkadia (where an unknown force drains the energy from the base's generators - something then repeated in the episode Black Sun, where a black hole slowly drains the base of its energy); Ring around the Moon (where the threat of an alien probe is illustrated by the fact that it forces a crew member to transmit vital information about the life-support system of the base); The Infernal Machine (where the title character, a giant robot, blackmails the humans to get energy he desperately needs); or Force of Life (where one of the crew members is possessed by an alien entity which needs energy and thus sucks it out from every source it can get, be it light, body heat or - finally - the generators of the moon base).

22. In the above-mentioned episode Force of Life, it is suggested that, ultimately, the alien entity which took possession of the body of the crew member did so because it needed to absorb energy in order to procreate. It is certainly not just a mere coincidence that in the following episode, Alpha Child, the birth of a human offspring, the first baby born on the moon base, is a key element in the narrative. The title A Matter of Life and Death refers to the classic British movie made by Michael Powell and Emeric Pressburger in 1946, which also deals with the frontiers between life and death.

23. In the above-mentioned episode Force of Life, for instance, the Alphans are involuntarily functioning as obstetricians for the alien birth, while in The Guardian of Piri they wrestle the dead planet Piri out of the control of a computer that had made the planet sterile because it subjected everything to the deadly principle of perfection.

24. Fageolle, Cosmos: 1999, 43.

25. Ibid., 15-16 and http://www.space1999.net/catacombs/main/crguide/vcwbmotd.html (accessed 10 August 2011). 
26. This even goes so far as the 'reviving' of old, and therefore dead, myths from earth: At the end of the episode Dragon's Domain, Dr Russell says to Commander Koenig: 'If we ever do find a new place to live, and if we succeed, we're going to need a whole new mythology,' because the deadly fight between a crew member and an alien monster, reminiscent of Saint George and the dragon, has thus 'put new life into an old myth.'

27. Marina Benjamin, Rocket Dreams: How the Space Age Shaped Our Vision of a World Beyond, New York: Free Press, 2003, 142-3. In 1959 Wernher von Braun voiced similar thoughts when justifying the need for space travel by saying that it might be the destiny of humankind to grant immortality not only to itself, but to life in general by transporting the 'spark of life' to other planets; see David F. Noble, The Religion of Technology: The Divinity of Man and the Spirit of Invention, New York: Knopf, 1997, 163.

28. Gerard K. O'Neill, 'The Colonization of Space,' Physics Today 27.9 (September 1974), 32-40. See also Benjamin, Rocket Dreams, 141. That another strong inspiration for the Darian episode was furnished by Douglas Trumbull's 1972 film Silent Running can be seen by the fact that Daria with its cupolas has a similar look to the 'ark' spaceships, depicted by Trumbull and designed to enshrine and preserve plants, already extinguished on earth.

29. In the episode The Last Sunset, Commander Koenig discusses the possibilities for setting up a colony elsewhere on the moon while inspecting photos taken by the Lunar Orbiter, launched in 1966; see http://www.space1999.net/catacombs/main/epguide/t11tls.html (accessed 10 August 2011). The 1969 Apollo 9 mission is particularly present in the series: In the episode The End of Eternity, pictures of astronaut Russell Schweickart (1935-) during his extra-vehicular activity and of the Lunar Module frame the doors of a pilot's quarters in order to show his enthusiasm for his work as an astronaut. The photographs reappear during a flashback to the year 1996 in the episode Dragon's Domain when they are hanging in Professor Bergman's former laboratory on the moon base.

30. http://www.space1999.net/catacombs/main/epguide/t04ratm.html (accessed 10 August 2011).

31. http://www.space1999.net/catacombs/main/crguide/vcwbvr.html (accessed 1 May 2011). On the occasion of the American première of the series on 4 August 1975 - and so still very distant from the later episode Voyager's Return - von Braun, in his position as president of the National Space Institute, welcomed and recommended Space: 1999 in a letter dating from 5 September 1975 and addressed to the broadcasting network's President Abe Mandell. Von Braun praised the series because, while 'freeing the creative imagination - so effectively accomplished in Space: 1999,' it 'imaginatively captures the excitement of living in the incredible age of space' and thus 'can only make the public more enthusiastic and concerned with the further exploration of our universe.' Von Braun's letter can be found at http://www.space1999.net/ catacombs/main/ pguide/wrefcbraun.html (accessed 10 August 2011).

32. Fageolle, Cosmos: 1999, 67.

33. See http://www.space1999.net/catacombs/main/crguide/vcwbvr.html (accessed 10 August 2011).

34. The Voyager mission was first called 'Mariner Jupiter-Saturn 1977 Mission' or 'MJS77' and it was only subsequently renamed 'Voyager' about six months prior to the launch of the two probes in the fall of 1977.

35. In the episode The Troubled Spirit, the presence of an alien surrounding does not even matter because it is ultimately through his concentrated fear that a crew member conjures up a revengeful specter which haunts the base.

36. See the interview with Mitchell presented in In the Shadow of the Moon, directed by David Sington, Discovery Film, 2007.

37. See Smith, Moon Dust, 52, 58, and especially the lectures given and articles written by Mitchell since 1973, summed up in Edgar Mitchell and Dwight Arnan Williams, The 
Way of the Explorer: An Apollo Astronaut's Journey Through the Material and Mystical Worlds, New York: Putnam, 1996.

38. Ibid., 59.

39. Cf. the following dialogue: Victor: 'John. Have you ever wondered just how and why we've survived?'/ Koenig: 'Not until now.'/ Victor: 'Have you got any answers?'/ Koenig: 'You're not referring to God, are you?'/ Victor: 'Oh, I don't know exactly. I'm a scientist, I don't know anything about God, but, no, a sort of "cosmic intelligence" is what I've got in mind.'

40. This concept of the universe as a brain was later also adapted in the episode Space Brain where the moon flies through a giant living entity which builds 'the centre of a whole galaxy ... maybe even hundreds of galaxies ... planets ... stars... strange life forms ... and in the middle of it all ... is this brain....'

41. Smith, Moon Dust, 61.

42. Eric Hobsbawm, Age of Extremes: The Short Twentieth Century, 1914-1991, London: Michael Joseph, 1994; Smith, Moon Dust, 292-3.

43. Preparations for the series began in 1972, the filming of the first episode started in November 1973; Muir, Exploring, 6 and 15.

44. Smith, Moon Dust, 121.

45. See, for instance, ibid., 252.

46. Arthur C. Clarke, 'Space Flight and the Spirit of Man,' Astronautics (October 1961); quoted Arthur C. Clarke, Voices from the Sky: Previews of the Coming Space Age, New York: Harper \& Row, 1965, 107.

47. It is perhaps significant that meanwhile also, the once so optimistic Star Trek series themselves have steered into more sceptical and pessimistic waters. After the spin-off series Star Trek: Deep Space 9 (1993-99) where a rather dark and bleak vision of the possibilities of diplomacy was displayed, with Star Trek: Voyager' (1995-2001), the producers created a starship which - like Moonbase Alpha - suffers the fate of an odyssey in unknown space, desperately striving to find a way back home to earth.

48. Smith, Moon Dust, 168. 